\title{
Recomendación de la utilización de herramientas de evaluación de riesgo familiar para el cáncer relacionado con mutaciones de los genes BRCA 1/2 en atención primaria
}

The USPSTF recommends the use of family risk assessment tools in primary care for cancer related to BRCA gene

mutations $1 / 2$

\section{Comentado de:}

US Preventive Services Task Force. JAMA. 2019;322(7):652665. PMID $31429903^{1}$

\section{Introducción}

Las mutaciones potencialmente dañinas de los genes de susceptibilidad al cáncer de mama (BRCA1/2) están asociados con un mayor riesgo de cáncer de mama, ovario, trompa de Falopio y peritoneal.

Para las mujeres de los Estados Unidos, el cáncer de mama es el más común (después del cáncer de piel no melanoma) y la segunda causa de muerte por cáncer. En la población general, las mutaciones BRCA $1 / 2$ ocurren en aproximadamente 1 de cada 300 a 500 mujeres y representan el $5 \%$ a $10 \%$ de los casos de cáncer de mama y $15 \%$ de los casos de cáncer de ovario ${ }^{2,3}$.

\section{Objetivos}

Actualizar la recomendación 2013 del Grupo de Trabajo de Servicios Preventivos de EE. UU. (USPSTF) sobre evaluación de riesgos, asesoramiento genético y pruebas genéticas para el cáncer relacionado con BRCA.

\section{Revisión de la evidencia}

La Fuerza de Tareas Preventivas de los EE.UU. (USPSTF), por sus iniciales en inglés) revisó la evidencia sobre evaluación de riesgos, asesoramiento genético y pruebas genéticas para mutaciones BRCA1/2 potencialmente dañinas en mujeres asintomáticas que nunca han sido diagnosticadas con cáncer relacionado a estas mutaciones, así como aquellas con un diagnóstico previo de cáncer de mama, ovario, trompas o peritoneo que han completado el tratamiento y se consideran libres de cáncer.

Además, la USPSTF revisó las intervenciones para reducir el riesgo de cáncer de mama, ovario, trompas o peritoneo en mujeres con potencial de mutaciones dañinas de BRCA $1 / 2$, incluyendo rastreo intensivo de cáncer, medicamentos y cirugía de reducción de riesgo.

\section{Resultados principales}

Para mujeres cuya historia familiar o personal está asociada con un mayor riesgo de mutaciones dañinas en los genes
BRCA1/2, o que tienen una ascendencia asociada con mutaciones genéticas BRCA1/2, existe evidencia de moderados beneficios con la evaluación de riesgos, el asesoramiento genético, las pruebas genéticas y las intervenciones.

Para mujeres cuya historia personal, familiares o la ascendencia no están asociados con un mayor riesgo de mutaciones dañinas en los genes BRCA1/2, existe evidencia adecuada de que los beneficios de la evaluación de riesgos, el asesoramiento genético, las pruebas genéticas y las intervenciones son pequeños o nulos.

Independientemente de la historia familia o personal, la USPSTF encontró evidencia adecuada de que los daños generales del riesgo de la evaluación, el asesoramiento genético, las pruebas genéticas y las intervenciones son pequeños a moderados.

\section{Conclusiones y recomendación}

La USPSTF recomienda que los médicos de atención primaria evalúen a las mujeres con antecedentes personales o familiares de cáncer de mama, ovario, trompas o peritoneo o que tienen una ascendencia asociada con mutaciones genéticas BRCA1/2 con una herramienta adecuada de evaluación breve del riesgo familiar.

Aquellas mujeres que utilizando la herramienta de evaluación de riesgo, tengan un resultado positivo deberían recibir asesoría genética y, si están indicadas después de la asesoría, pruebas genéticas (Recomendación tipo B).

La USPSTF se expide en contra de la evaluación de riesgos de rutina, asesoramiento genético o pruebas genéticas para mujeres cuyos antecedentes personales o familiares o su ascendencia no están asociados con mutaciones del gen BRCA1/2 potencialmente dañinas. (Recomendación tipo D).

Fuente de financiamiento / Conflicto de interés de los autores: Todos los autores completaron el Formulario ICMJE para la divulgación de posibles conflictos de intereses.

\section{Comentario}

En Argentina, según las estimaciones de incidencia del Observatorio Global de Cáncer de la OMS, el cáncer de mama (CM) es el cáncer más frecuente (excluyendo cáncer de piel no melanoma) con una tasa de incidencia de 73 casos por cada 100.000 mujeres, representando el $17 \%$ de todos los tumores malignos y casi un tercio de los cánceres femeninos. En el año 2016, la mortalidad por cáncer de mama femenino en Argentina correspondió a 17,8 defunciones por 100.000 mujeres ${ }^{4}$. Entre el 5 y el $10 \%$ de los casos de CM son hereditarios y su aparición está asociada a la herencia de un gen mutado, deficitario en su función. Un tercio de los casos de CM presentan agregación familiar, es decir que aparecen en dos o más individuos pertenecientes a una misma genealogía. El impacto de los antecedentes familiares en el riesgo de desarrollar CM, puede ser calculado en forma empírica utilizando la información clínica familiar y algunos modelos de cálculo ya establecidos, que sirven como herramienta de aproximación en la cuantificación del riesgo ${ }^{5}$. 
El Síndrome de Cáncer de Mama/Ovario Hereditario, provocado por mutaciones en los genes BRCA1 y BRCA2 es el más común de los síndromes de CM hereditario, y el riesgo acumulado de desarrollar esta enfermedad en individuos portadores de mutaciones en estos genes pueden alcanzar valores de hasta $80 \%$ a lo largo de la vida. Existen además de los dos principales, otros tumores dentro del espectro de este síndrome (páncreas, próstata, melanoma, etc.) y las estrategias de prevención han logrado disminuir la mortalidad de estos pacientes ${ }^{5}$.

Las estimaciones de la prevalencia de mutaciones potencialmente dañinas de BRCA1/2 son variables según la población. Mientras que la prevalencia es de $0,2 \%$ a $0,3 \%$ en la población general de mujeres, es de $6 \%$ en mujeres con aparición de cáncer antes de los 40 años de edad, y de aproximadamente $2 \%$ en la población de mujeres judías de ascendencia Ashkenazi. En un meta-análisis de estudios en los cuales el reclutamiento se basó en historia familiar de cáncer de mama u ovario, la prevalencia de la mutación BRCA 1 fue de 13,6\%, de BRCA, de 7,9\% y de cualquiera de las dos mutaciones, de $19,8 \%{ }^{6}$.

En ese contexto, la identificación de mujeres en riesgo de presentar mutaciones BRCA1 y BRCA 2, esta recomendada ${ }^{7,8}$. Las herramientas de estratificación de riesgo familiar, destinadas para su uso en atención primaria, obtienen información sobre factores asociados con una mayor probabilidad de mutaciones BRCA1/2, incluyendo antecedentes familiares, personales y ascendencia (ej. judía Ashkenazi). La revisión de la evidencia disponible por parte de la USPSTF determinó que estas herramientas son predictores clínicamente útiles, con una sensibilidad estimada del 77 al $100 \%$.

\section{Conclusiones de la comentadora}

La identificación y caracterización correcta de pacientes con alto riesgo de padecer CM es un estándar de cuidado que debe ofrecerse y estar disponible como un componente más de la práctica clínica habitual.

La correcta cuantificación del riesgo al que está expuesto un individuo con antecedentes personales o familiares de CM forma parte del proceso de asesoramiento genético oncológico.

Teniendo en cuenta de que hablamos de un grupo muy especifico de pacientes, es válido resaltar la utilidad de poder disponer en atención primaria de herramientas que guíen nuestra práctica y conducta a seguir.

Yanina Avendaño [ Servicio de Medicina Familiar y Comunitaria, Hospital Italiano de Buenos Aires yanina.avendano@hospitalitaliano.org.ar ]

Avendaño Y Recomendación de la utilización de herramientas de evaluación de riesgo familiar para el cáncer relacionado con mutaciones de los genes BRCA 1/2 en atención primaria. Evid Actual Pract Ambul. 2019;22(3):e002022. Comentado de: US Preventive Services Task Force. Risk Assessment, Genetic Counseling, and Genetic Testing for BRCA-Related Cancer: US Preventive Services Task Force Recommendation Statement.JAMA. 2019;322(7):652-665. PMID 31429903

\section{Referencias}

1. Owens DK, Davidson KW, Krist AH, Barry MJ, Cabana M, Caughey AB, et al. Risk Assessment, Genetic Counseling, and Genetic Testing for BRCA-Related Cancer: US Preventive Services Task Force Recommendation Statement. JAMA. 2019;322(7):652. Available from: 10.1001/jama. 2019.10987.

2. Peto J, Collins N, Barfoot R, Seal S, Warren W, Rahman N, et al. Prevalence of BRCA1 and BRCA2 gene mutations in patients with early- onset breast cancer. Journal of the National Cancer Institute. 1999;91(11):943-949. Available from: 10.1093/jnci/91.11.943.

3. Whittemore AS, Gong G, John EM, McGuire V, Li FP, Ostrow KL, et al. Prevalence of BRCA1 mutation carriers among U.S. non-Hispanic Whites. Cancer epidemiology, biomarkers \{\&amp; prevention : a publication of the American Association for Cancer Research, cosponsored by the American Society of Preventive Oncology. 2004 dec;13(12):2078-83.

4. Ballesteros I, Abriata MG. Análisis de Situación de Salud por Cáncer. Argentina, 2018; 2018. Available from: http://www.msal.gob.ar/images/stories/ bes/graficos/0000001386cnt-20181213-boletin-epidemiologia.pdf

5. Núñez LM, Pesce V, et al.. Pautas para la deteccion y estudio de casos de alto riesgo de cancer de mama heredo familiar; 2012. Available from: http://iah.salud.gob.ar/doc/Documento207.pdf.

6. Nelson HD, Fu R, Goddard K, Mitchell JP, Okinaka-Hu L, Pappas M, et al. Risk Assessment, Genetic Counseling, and Genetic Testing for BRCARelated Cancer: Systematic Review to Update the U.S. Preventive Services Task Force Recommendation. Risk Assessment, Genetic Counseling, and Genetic Testing for BRCA-Related Cancer: Systematic Review to Update the US Preventive Services Task Force Recommendation. 2013;(101):366

7. Baretta Z, Mocellin S, Goldin E, Olopade OI, Huo D. Effect of BRCA germline mutations on breast cancer prognosis: A systematic review and meta-analysis. Medicine (United States). 2016;95(40). Available from: 10.1097/MD.0000000000004975.

8. Winters S, Martin C, Murphy D, Shokar NK. Breast Cancer Epidemiology, Prevention, and Screening. Progress in molecular biology and translational science. 2017;151:1-32. Available from: 10.1016/bs.pmbts.2017.07.002. 